This item was submitted to Loughborough's Research Repository by the author.

Items in Figshare are protected by copyright, with all rights reserved, unless otherwise indicated.

\title{
Economies of scale in UK building societies: a re-appraisal using an
} entry/exit model

PLEASE CITE THE PUBLISHED VERSION

LICENCE

CC BY-NC-ND 4.0

\section{REPOSITORY RECORD}

Drake, Leigh M., and Richard Simper. 2019. "Economies of Scale in UK Building Societies: A Re-appraisal Using an Entry/exit Model”. figshare. https://hdl.handle.net/2134/433. 
This item was submitted to Loughborough's Institutional Repository by the author and is made available under the following Creative Commons Licence conditions.

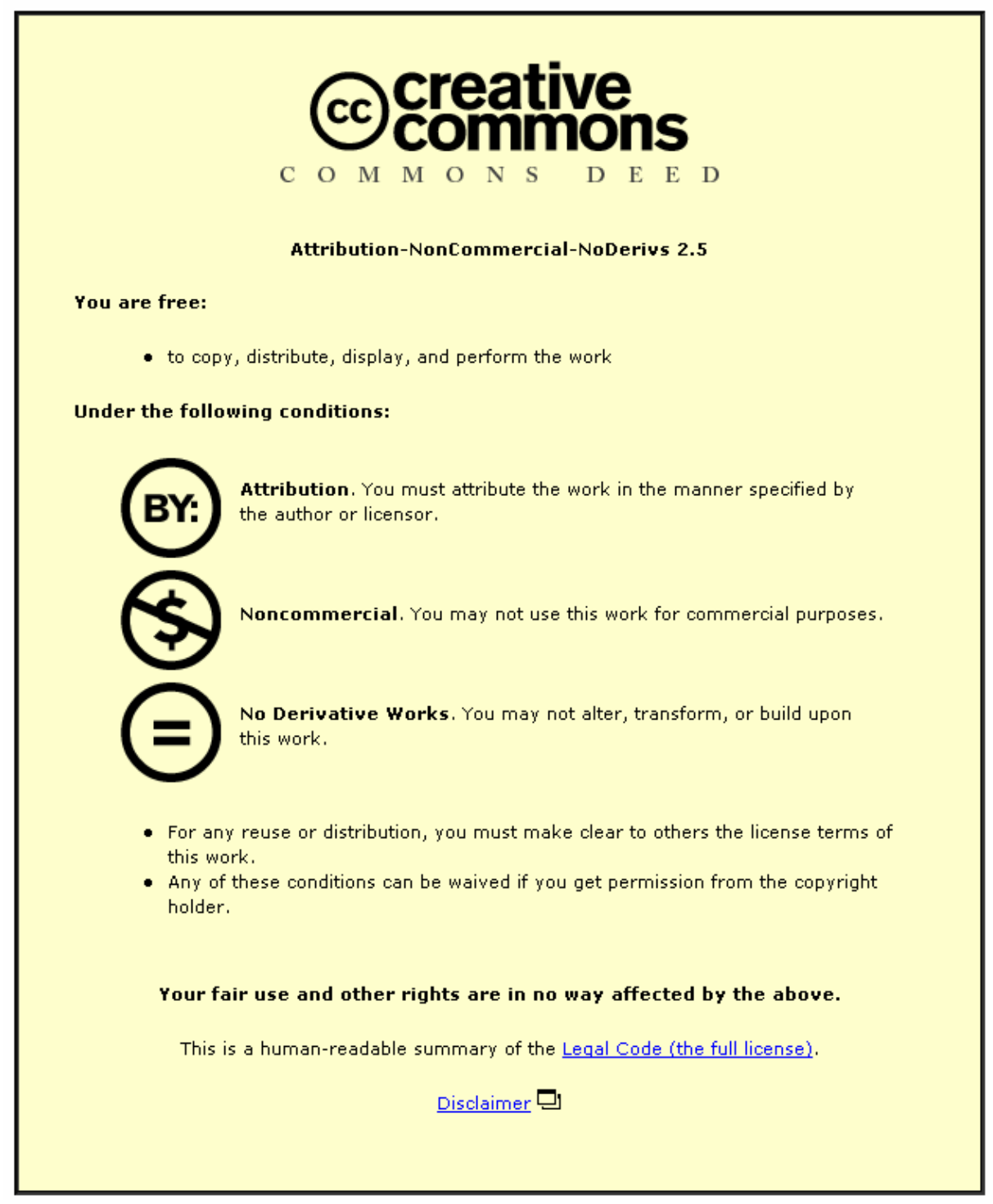

For the full text of this licence, please go to: http://creativecommons.org/licenses/by-nc-nd/2.5/ 
Department of Economics

Economic Research Paper No. 00/8

Economies of Scale in UK Building

Societies: A Re-Appraisal Using

An Entry/Exit Model

Leigh Drake and Richard Simper

May 2000

Loughborough

University 
Centre for International, Financial and Economics Research Department of Economics

Loughborough University

Loughborough

Leics., LE11 3TU

UK

Tel: $+44(0) 1509222734$

Fax: + 44 (0) 1509223910

Email: E.J.Pentecost@lboro.ac.uk

Director : $\quad$ Dr Eric J Pentecost

Deputy Director : Professor C J Green

Associate Directors:

Professor Kenneth J Button,George Mason University, USA

Professor Peter Dawkins, University of Melbourne, Australia

Professor Robert A Driskill, Vanderbilt University, USA

Professor James Gaisford, University of Calgary, Canada

Professor Andre van Poeck, University of Antwerp, Belgium

Professor Amine Tarazi, University of Limoges, France 


\title{
Economies of Scale in UK Building Societies:
}

\section{A Re-Appraisal Using An Entry/Exit Model}

\author{
Leigh Drake* and Richard Simper \\ Department of Economics, Loughborough University, Loughborough, England, \\ LE11 $3 T U$
}

\begin{abstract}
This study advances an entry/exit model to analyse the scale efficiency of UK building societies. We find that there are considerable divergences across building societies in levels of scale efficiency and also in technological change during the sample period 1992-1997. The paper also finds that scale economies and technological change estimates are dependent on whether the econometrician balances a panel data set or utilises the entry/exit model based on Dionne et al's (1998) specification. In general, scale economies in UK building societies are found to be more significant and more pervasive than in previous studies.
\end{abstract}

JEL classification: C23; C52; G21

Keywords: Building Societies; Scale efficiency; Technological Change; Cost frontier Analysis; Entry/Exit Model

\section{Introduction}

UK building societies are mutual institutions regulated by statute and historically were restricted, in the main, to raising funds from retail deposits and intermediating these funds into mortgage lending. The Building Societies Act 1986, however, enabled building societies to diversify into a much wider range of housing related and retail financial services and to diversify their assets, within limits, away from the traditional

* Corresponding author. Tel +44-1509-222707; fax: +442-1509-23910.

E-Mail address: L.M.Drake@lboro.ac.uk 
(Class 1) mortgage lending. The powers to hold so-called Class 2 and Class 3 assets enabled building societies to undertake commercial and second mortgage lending, unsecured consumer lending, and to make investments in subsidiaries and associated bodies. The more recent 1997 legislation removed most of the remaining restrictions and building societies can now effectively be viewed as mutual retail banks or mutual retail financial services organisations.

In addition to the diversification powers outlined above, the UK building society movement has also undergone considerable consolidation in recent years, both as a consequence of mergers within the mutual building society sector, and due to the conversion of a number of the larger building societies to plc bank status. In 1992 for example, there were 86 UK building societies, but by 1997 this number had fallen to 70 . This consolidation phase in the UK building society sector echoes the trend towards rationalisation and mergers evident in UK and US banking and indeed in financial services markets around the world. Although the converted building societies do receive 5 years protection from take-over following plc conversion, it seems likely that we will ultimately see further consolidation in UK banking, following the recent examples of Lloyds-TSB and the Royal Bank of Scotland and Nat West, and some of this may well involve the so called "mortgage banks".

Against this backdrop of consolidation and increased merger activity, it is clear that the issue of economies of scale is extremely important in the context of UK banking and retail financial services. In contrast to the wealth of research conducted in this area in the US, however, there has been a dearth of such academic research in the UK. This possibly reflects the small number of banks operating in the UK compared to the huge sample sizes available in the US. Despite the recent decline in numbers, however, UK building societies do represent a reasonable sample size for academic research, especially in the context of panel data samples. Furthermore, the diversification of building societies in recent years, coupled with the conversion of a number of the larger societies into plc banks, implies that this sector can provide a highly informative case study of the nature of scale economies and the size efficiency relationship in the UK retail financial services market. 
Although previous empirical work has been conducted into UK building societies by, for example, Hardwick (1989), Drake (1992) and Drake and Weyman-Jones (1996), the data utilised was typically cross section and related to the 1980s. In general these studies tended to indicate that only modest economies of scale were present and that they were exhausted at relatively low asset levels. This echoed the type of evidence emerging from the US banking literature in the 1980s and implied that alternative explanations should be sought for large scale mergers.

Evidence has recently emerged from the US, however, which suggests that scale economy estimates can be sensitive to the particular cost function specification and to the impact of technological innovation on costs (see Berger and Mester, 1997). The latter point also suggests that scale economy estimates may also be sample specific. In particular, it may be the case that the results obtained using data from the 1990s may be very different from those obtained during the 1980s due to the significant impact of new technology over the last decade or so.

Hence, the aim of this paper is to provide a reappraisal of the evidence on scale economies in UK building societies, thereby providing some important insights in respect of the market for retail financial services in the UK. In order to do this we specify and estimate a translog cost function using a panel data set drawn from the 1990s. We pay particular attention, however, to the robustness of the cost model and to the possibility of mis-specification which could bias the scale economy estimates. A particular innovation in this paper is the incorporation of both Hunter and Timme's (1991) technological change specification and Dionne et al's (1998) entry/exit equation, together with the application of a general to specific testing procedure applied to the translog cost function specification. The specification of an entry/exit model may be particularly appropriate for the building society sector given the propensity for exit via mergers and conversion.

The remainder of the paper is structured as follows: section II outlines the estimation methodology; section III provides details of the data; section IV provides a discussion of the estimations and results, and finally, section V concludes. 


\section{Estimation Methodology}

To formalise the problem we can draw on the following model. Begin by defining the variables:

$$
\mathrm{C}\left(\mathrm{y}_{\mathrm{it}}, \mathrm{w}_{\mathrm{it}}, \mathrm{t}\right) \equiv \min _{\mathrm{x}_{\mathrm{it}}}\left\{\sum_{\mathrm{m}=1}^{\mathrm{M}} \mathrm{w}_{\text {mit }} \mathrm{x}_{\text {mit }}: \mathrm{y}_{\mathrm{it}}=\mathrm{F}\left(\mathrm{x}_{\mathrm{it}}, \mathrm{t}\right)\right\}
$$

where $\quad y_{i t}-$ a vector of outputs of society i at period t, $y_{i t} \in R_{+}^{s}$

$$
\begin{aligned}
& \mathrm{x}_{\mathrm{it}}-\mathrm{a} \text { vector of input quantities, } \mathrm{x}_{\mathrm{it}} \in \mathrm{R}_{+}^{\mathrm{m}} \\
& \qquad{ }_{\text {it }} \in{ }^{\mathrm{m}} \text {, and } \\
& \mathrm{t}-\mathrm{a} \text { index of technological change. }
\end{aligned}
$$

$\mathrm{F}\left(\mathrm{x}_{\mathrm{it}}, \mathrm{t}\right)$ is the society's input requirement set of feasible input bundles $\mathrm{x}_{\mathrm{it}}$, that can be used to obtain a predetermined output vector, $y_{i t}$ (such as consumer loans). The production function is also at least twice continuously differentiable, increasing and concave in $\mathrm{x}_{\mathrm{it}}$. In addition, the cost function $\mathrm{C}\left(\mathrm{y}_{\mathrm{it}}, \mathrm{w}_{\mathrm{it}}, \mathrm{t}\right)$ is increasing in $\mathrm{y}_{\mathrm{it}}$ and $\mathrm{w}_{\mathrm{it}}$, homogeneous of degree zero, and concave in $\mathrm{w}_{\mathrm{it}}$.

The model estimated in this paper is an extension of Hunter and Timme's (1991) technological change specification and Dionne et al's (1998) entry/exit equation. That is, we utilise the first specification to obtain two types of technological change estimates, and the second specification to take account of the unbalanced panel data set. The latter is particularly important when analysing UK building societies as the sector has undergone a considerable degree of consolidation in recent years. This consolidation is attributable both to mergers within the mutual building society sector and to the conversion of some of the larger building societies to Plc bank status.

Hence, the data set utilised in this paper is unbalanced because some building societies had incomplete records over the total sample. In standard estimates of cost efficiency and scale economies, those building societies with incomplete records would have been excluded from the sample (see for example, Berger (1993), DeYoung (1997), and for a bank branch X-efficiency study Berger, Leusner and Mingo (1997)). This would imply that 17 building societies over the complete sample would be excluded from 
our estimations. However, Olley and Pakes (1998) have argued that "if firms' exit decisions depend on their perceptions of their future productivity, and if their perceptions are partially determined by their current productivity, then a balanced panel sample will be selected, in part, on the basis of the unobserved productivity realisations. This will generate a selection bias of a particular form in the production function estimates." (page. 1271).

In addition, we can also think of an unbalanced panel data sample as one where there are incomplete returns on all building societies, for reasons which are unknown to the econometrician. To account for these different scenarios, Dionne et al (1998) have advanced an exit/entry model, that allows firms to rejoin panel data samples with a complete year of data. They argue that, "exit cannot be ignored in general and that it cannot be avoided by sub-balancing. The cost model must be estimated jointly with the exit model to obtain consistent parameters and standard errors." (page. 310). To determine the effects of entry or exit of building societies in our sample, the cost function is jointly estimated with the exit/entry equations and we test for significance following a general to specific methodology.

In this case, the cost function in equation (1) can be approximated by the translog cost function with share equations $\mathrm{S}_{\text {mit }}$,

$$
\begin{array}{ll}
\ln C_{i t}=\ln C\left(y_{i t}, w_{i t}, B_{i t}, A_{t}\right)+b_{i t}+d_{i t}+u_{i t} & \\
S_{\text {mit }}=S_{m}\left(y_{i t}, w_{i t}, B_{i t}, A_{t}\right)+\varpi_{\text {mit }} \quad m=1, \ldots, M-1,
\end{array}
$$

and including the entry and exit equations

$$
\begin{aligned}
& b_{i t}^{*}=\alpha^{\prime} X_{i t}+\varepsilon_{i t} \\
& b_{i t}^{*}=\left\{\begin{array}{l}
1 \text { if } b_{i t}^{*} \geq 0 \\
0 \text { otherwise }
\end{array}\right\}
\end{aligned}
$$

and

$$
\begin{aligned}
& \mathrm{d}_{\mathrm{it}}^{*}=\pi^{\prime} \mathrm{Z}_{\mathrm{it}}+v_{\mathrm{it}} \\
& \mathrm{d}_{\mathrm{it}}^{*}=\left\{\begin{array}{l}
1 \text { if } \mathrm{d}_{\mathrm{it}}^{*} \geq 0 \\
0 \text { otherwise }
\end{array}\right\}
\end{aligned}
$$


where, $B_{i t}$ is the number of branches for society $i$ at time $t ; A_{t}$ is a technological factor, that is proxied by using time dummies and setting $A_{1}=0 ; b_{i t}=1$ if a building society is entering the sample at period $\mathrm{t}\left(\mathrm{b}_{\mathrm{it}}=0\right.$, otherwise $) ; \mathrm{d}_{\mathrm{it}}=1$ if a building society is exiting the sample at period $\mathrm{t}\left(\mathrm{d}_{\mathrm{it}}=0\right.$, otherwise $) ; \mathrm{u}_{\mathrm{it}}$ and $\varpi_{\mathrm{it}}$ are i.i.d. disturbances uncorrelated with the explanatory variables with $\mathrm{E}\left[\mathrm{u}_{\mathrm{it}}, \bar{\varpi}_{1 \mathrm{lit}}, \ldots, \bar{\varpi}_{\mathrm{M}-\mathrm{lit}}\right]=0$; $\operatorname{Var}\left[\mathrm{u}_{\mathrm{it}}, \varpi_{1 \mathrm{it}}, \ldots, \varpi_{\mathrm{M}-\mathrm{lit}}\right]=\sum_{\mathrm{u} \sigma} ; \varepsilon_{\mathrm{it}}$ and $v_{\mathrm{it}}$ are disturbances uncorrelated with the explanatory variables, with properties, $\mathrm{E}\left[\varepsilon_{\mathrm{it}}\right]=\mathrm{E}\left[\mathrm{v}_{\mathrm{it}}\right]=0, \operatorname{Var}\left[\varepsilon_{\mathrm{it}}\right]=\sigma_{\varepsilon_{\mathrm{it}}}^{2}, \operatorname{Var}\left[\mathrm{v}_{\mathrm{it}}\right]=\sigma_{v_{\mathrm{it}}}^{2}$, and $\mathrm{X}_{\mathrm{it}}, \mathrm{Z}_{\mathrm{it}}$ are vectors of explanatory variables in the entry and exit equations.

However, given the cost function in equation (1) it has been argued in the literature that there is a possible identification problem in production modeling, especially when a single industry is estimated due to the fact that certain cost items influence the size of the bank (see Thomas (1985), Chapter 8). In our specification, this problem can be discounted for two reasons. Firstly, we assume that the larger building societies had a greater share of the market and were more able to price discriminate on products than their smaller competitors. The market is therefore assumed to be imperfectly competitive. The second assumption concerns the error structure of the translog cost function and share equations. All share equation errors are contemporaneously correlated with the translog cost function error term. The nonzero contemporaneous error could be attributable to a mis-specification of the translog cost function, i.e., the result of errors in cost minimisation by managers and other factors that are not modeled explicitly. Examples might include regional rent and price differences for offices, or variations in the ability of managers across building societies. The latter two assumptions allow us to estimate a cost function for the industry where the building societies have similar inputs and outputs, but different cost structures. That is, we estimate a model that excludes random and fixed effects thereby further simplifying the distributional assumptions of Dionne et al (1998).

In addition, we extend Dionne et al's (1998) entry/exit specification based on the translog cost function specification by including a $3^{\text {rd }}$ order polynomial in time, see Hunter and Timme (1991). The most general specification, Model 1AA, which concerns 
the estimation of scale economies and technological change, can be written as follows (where we drop the time subscript to reduce notation).

$$
\begin{aligned}
\ln \left(\mathrm{C}_{\mathrm{i}}\right)= & \operatorname{const}_{\ln \left(\mathrm{C}_{\mathrm{i}}\right)}+\mathrm{b}_{\mathrm{i}}+\mathrm{d}_{\mathrm{i}}+\sum_{\mathrm{i}=1}^{3} \alpha_{\mathrm{i}} \ln \tilde{\mathrm{y}}_{\mathrm{i}}+\frac{1}{2} \sum_{\mathrm{i}=1}^{3} \sum_{\mathrm{j}=1}^{3} \sigma_{\mathrm{ij}} \ln \tilde{\mathrm{y}}_{\mathrm{i}} \ln \tilde{\mathrm{y}}_{\mathrm{j}}+\sum_{\mathrm{m}=1}^{3} \beta_{\mathrm{m}} \ln \tilde{\mathrm{w}}_{\mathrm{m}} \\
& +\frac{1}{2} \sum_{\mathrm{m}=1}^{3} \sum_{\mathrm{n}=1}^{3} \gamma_{\mathrm{mn}} \ln \tilde{\mathrm{w}}_{\mathrm{m}} \ln \tilde{\mathrm{w}}_{\mathrm{n}}+\frac{1}{2} \sum_{\mathrm{i}=1}^{3} \sum_{\mathrm{m}=1}^{3} \delta_{\mathrm{im}} \ln \tilde{\mathrm{y}}_{\mathrm{i}} \ln \tilde{\mathrm{w}}_{\mathrm{m}} \\
& +\tau_{\mathrm{B}} \ln \mathrm{B}+\frac{1}{2} \tau_{\mathrm{BB}} \ln \mathrm{B}^{2}+\sum_{\mathrm{m}=1}^{3} \tau_{\mathrm{Bm}} \ln \mathrm{B} \ln \tilde{\mathrm{w}}_{\mathrm{m}}+\sum_{\mathrm{i}=1}^{3} \tau_{\mathrm{Bi}} \ln \mathrm{B} \ln \tilde{\mathrm{y}}_{\mathrm{mi}} \\
& +\eta_{\mathrm{T}} \mathrm{T}+\frac{1}{2} \eta_{\mathrm{TT}} \mathrm{T}^{2}+\sum_{\mathrm{i}=1}^{3} \eta_{\mathrm{Ti}} \mathrm{T} \ln \tilde{\mathrm{y}}_{\mathrm{i}}+\sum_{\mathrm{m}=1}^{3} \eta_{\mathrm{Tm}} \mathrm{T} \ln \tilde{\mathrm{w}}_{\mathrm{m}} \\
& +\frac{1}{2} \sum_{\mathrm{i}=1}^{3} \eta_{\mathrm{TTi}} \mathrm{T}^{2} \ln \tilde{\mathrm{y}}_{\mathrm{i}}+\frac{1}{2} \sum_{\mathrm{m}=1}^{3} \eta_{\mathrm{TTm}} \mathrm{T}^{2} \ln \tilde{\mathrm{w}}_{\mathrm{m}}+\frac{1}{2} \sum_{\mathrm{i}=1}^{3} \sum_{\mathrm{j}=1}^{3} \eta_{\mathrm{Tij}} \mathrm{T} \ln \tilde{\mathrm{y}}_{\mathrm{i}} \ln \tilde{\mathrm{y}}_{\mathrm{j}}+\mathrm{u}_{\mathrm{i}}
\end{aligned}
$$

Using Shephard's Lemma , the input share equations corresponding to equation (5) are as follows, ${ }^{1}$

$$
\begin{array}{r}
\mathrm{S}_{\mathrm{mit}}=\beta_{\mathrm{m}}+\sum_{\mathrm{n}=1}^{3} \gamma_{\mathrm{mn}} \ln \tilde{\mathrm{w}}_{\mathrm{n}}+\sum_{\mathrm{i}=1}^{3} \delta_{\mathrm{im}} \ln \tilde{\mathrm{y}}_{\mathrm{i}}+\sum_{\mathrm{m}=1}^{3} \tau_{\mathrm{Bm}} \ln \mathrm{B}+\eta_{\mathrm{Tm}} \mathrm{T}+\frac{1}{2} \eta_{\mathrm{TTm}} \tilde{\mathrm{w}}_{\mathrm{m}}+\bar{\varpi}_{\mathrm{i}} \\
\mathrm{m}=1, \ldots, \mathrm{M}
\end{array}
$$

and the entry and exit equations are specified as,

$$
\begin{aligned}
& \mathrm{b}_{\mathrm{i}}^{*}=\text { const }_{\mathrm{bi}}+\sum_{\mathrm{k}=1}^{3} \mathrm{~b}_{\mathrm{k}} \ln \tilde{\mathrm{y}}_{\mathrm{k}}+\sum_{\mathrm{h}=1}^{3} \mathrm{~b}_{\mathrm{h}} \ln \tilde{\mathrm{w}}_{\mathrm{h}}+\mathrm{b}_{\mathrm{T}} \mathrm{T}+\mathrm{b}_{\mathrm{B}} \ln \mathrm{B}+\varepsilon_{\mathrm{i}} \\
& \mathrm{d}_{\mathrm{i}}^{*}=\text { const }_{\mathrm{di}}+\sum_{\mathrm{g}=1}^{3} \mathrm{~d}_{\mathrm{g}} \ln \tilde{\mathrm{y}}_{\mathrm{g}}+\sum_{\mathrm{h}=1}^{3} \mathrm{~d}_{\mathrm{h}} \ln \tilde{\mathrm{w}}_{\mathrm{h}}+\mathrm{d}_{\mathrm{T}} \mathrm{T}+\mathrm{d}_{\mathrm{B}} \ln \mathrm{B}+\mathrm{v}_{\mathrm{i}}
\end{aligned}
$$

where, ln denotes the natural logarithm of a variable, $\tilde{\mathrm{z}} \equiv \ln (\mathrm{z} / \overline{\mathrm{z}})$ where $\overline{\mathrm{Z}}$ is the sample mean of $z, b_{i}$ and $d_{i}$ are entry and exit dummy variables, $b_{i}^{*}$ is the entry equation, $d_{i}^{*}$ is the exit equation explained in equations (3) and (4). We impose two sets of parameter restrictions on the system of equations; Young's theorem requires that the second order parameters of the cost function must be symmetric, that is $\sigma_{\mathrm{ij}}=\sigma_{\mathrm{ji}}$ and $\eta_{\mathrm{Tij}}=\eta_{\mathrm{Tji}}$ for all

\footnotetext{
${ }^{1}$ As the cost shares sum to unity, one share equation must be omitted from the estimation in order to avoid a singular covariance matrix. The maximum likelihood estimates are invariant to the choice of the omitted share equation, however, and we elect to omit $\mathrm{S} 1$.
} 
$\mathrm{i}, \mathrm{j}$ and $\gamma_{\mathrm{mn}}=\gamma_{\mathrm{nm}}$ for all $\mathrm{m}, \mathrm{n}$. In addition, to ensure linear homogeneity of prices, $\sum_{\mathrm{m}} \beta_{\mathrm{m}}=1, \sum_{\mathrm{mn}} \gamma_{\mathrm{mn}}=0, \sum_{\mathrm{im}} \delta_{\mathrm{im}}=0, \sum_{\mathrm{m}} \eta_{\mathrm{Tm}}=0, \sum_{\mathrm{m}} \eta_{\mathrm{TTm}}=0, \sum_{\mathrm{h}} \mathrm{b}_{\mathrm{h}}=0$ and $\sum_{\mathrm{h}} \mathrm{d}_{\mathrm{h}}=0$.

To calculate overall economies of scale (OES), the translog cost function (5) is differentiated with respect to output (Panzar and Willig (1977)),

$$
\mathrm{OES}=\mathrm{C}\left(\mathrm{y}_{\mathrm{it}}, \mathrm{w}_{\mathrm{it}}, \mathrm{A}_{\mathrm{t}}\right) / \sum_{\mathrm{i}} \mathrm{y}_{\mathrm{it}} \mathrm{MC}_{\mathrm{i}}=\partial \ln \mathrm{C}_{\mathrm{it}} / \partial \ln \mathrm{y}_{\mathrm{it}}
$$

Where $\mathrm{MC}_{\mathrm{i}}$ is the marginal cost with respect to the $i$ th output and $\xi=\partial \ln \mathrm{C}_{\mathrm{it}} / \partial \ln \mathrm{y}_{\mathrm{it}}$ is the cost elasticity of the $i$ th output. If $\xi \succ 1$, building societies experience diseconomies of scale, if $\xi \prec 1$, they exhibit increasing returns and if $\xi=1$ this is indicative of constant returns to scale in the building society movement. These results imply that if an equal proportionate increase in all inputs leads to a less than proportionate increase in costs, there are economies of scale.

There are two types of technical change that we can estimate from the translog cost function (see Hunter and Timme (1991)). The first is an overall measure which is the percentage change in the cost of inputs resulting from changes in intermediary technology, holding everything else in equation (5) constant (see also Simper (1999), and Glass and McKillop (1992) for an application to an Irish Bank). If TECH is less than zero, then a building societies outputs can be produced at a lower total cost as a result of technological change.

$$
\mathrm{TECH}=\left(\partial \ln \mathrm{C}_{\mathrm{i}} / \partial \mathrm{T}\right)=\eta_{\mathrm{T}}+\eta_{\mathrm{TT}} \overline{\mathrm{T}}+\overline{\mathrm{T}} \sum_{\mathrm{i}} \eta_{\mathrm{Ti}} \ln \overline{\mathrm{y}}_{\mathrm{i}}+\sum_{\mathrm{j}} \eta_{\mathrm{jT}} \ln \overline{\mathrm{p}}_{\mathrm{j}}
$$

The second technical change concept measures the scale biased technological change of UK building societies along the ray average cost curve. The scale biased technical change measure is given by equation (11).

$$
\operatorname{TECSB}=\left(\partial \ln \mathrm{C}_{\mathrm{i}} / \partial \ln \mathrm{y}_{\mathrm{i}} \partial \mathrm{T}\right)=\sum_{\mathrm{i}} \eta_{\mathrm{Ti}}+\sum_{\mathrm{i}} \eta_{\mathrm{TTi}} \mathrm{T}+\sum_{\mathrm{i}} \eta_{\mathrm{Tii}} \ln \overline{\mathrm{y}}_{\mathrm{i}}
$$


If TECHSB is less than zero then, for a given product mix, technological change causes larger building societies to be more efficient over time than their smaller competitors and hence helps to minimise costs.

\section{Data}

The sample of building societies include all those that were listed in the Building Societies Association (BSA) year books from 1992 - 1997 (86 societies to 70 societies respectively). The modelling methodology in this paper follows the standard intermediation approach of Sealey and Lindley (1976) in which the financial institution is assumed to intermediate deposits into various categories of earning assets using labour and capital inputs. Hence, deposits are specified as inputs alongside the usual economic factors of production.

In this paper we specify 3 inputs and 3 outputs (see Table 1 for summary statistics). Total deposits include both retail and wholesale funds and the input price is calculated as interest costs per pound of total deposits. The input price for labour is calculated as total employment costs divided by the number of full time equivalent (FTE) employees. In calculating FTE numbers, full time staff are given a weight of 1 and part time staff a weight of 0.5 .

Finally, capital costs are calculated as all other non-labour and non-interest expenses, including items such as depreciation and auditing. The input price of capital is calculated by dividing capital expenses by the net book value of fixed assets. This is also the approach adopted, inter alia, by Hardwick (1989) and Drake and Wyman-Jones (1996).

\section{INSERT TABLE 1}

The first output is mortgages secured on residential property (Class 1 loans), the second is loans secured on land and unsecured loans (Class 2 and Class 3 loans). Finally 
to take account of non-traditional building society business, the third output is the summation of commissions and other fee income from operations as well as interest received on liquid assets. This final output category reflects the fact that many of the new business areas will fee income rather than the traditional margin income.

In addition to enable further analysis, societies were sub-divided in terms of their total asset size. Group A had assets over $£ 5$ billion, asset group B $£ 0.5$ billion - $£ 5$ billion, asset group $\mathrm{C} £ 0.12$ billion - $£ 0.5$ billion, asset group D $£ 0.05$ billion - $£ 0.12$ billion, and asset group E were building societies with total assets up to $£ 0.05$ billion.

\section{Estimation and Results}

The summary regularity test results, and economies of scale and technological change estimates for the entry/exit technological change model are presented in Tables 2 and 3. In the former Table, we have presented the results from the augmented branch entry/exit model, and in the latter we present estimates from models excluding the number of branches. Therefore, our econometric methodology is one in which we test from the most general specification stage 1AA which includes the control variable branches, to the standard translog cost function estimates in Table 3. In general, we estimate a system of equations over 3 general to specific stages (stage 1 to stage 3 ) and also by a step down procedure within each stage (A to B which tests the null hypothesis of insignificant technological change parameters). Excluding the branch control variables in the specifications, the most general model is given by stage 1A where the complete system of equations, including entry/exit dummy variables, entry and exit equations and $3^{\text {rd }}$ order polynomials in time were estimated. Stage $2 \mathrm{~A}$ differs from stage $1 \mathrm{~A}$ by excluding the entry/exit equations; and stage $3 \mathrm{~A}$ differs from stage $2 \mathrm{~A}$ by excluding the entry/exit dummy variables. Hence, stage $3 \mathrm{~A}$ is the standard translog cost function with $3^{\text {rd }}$ order time polynomial to capture technological change (see for example, Hunter and Timme (1992)), and stage 3B is the standard cost function usually reported in empirical tests of economies of scale (see for example, Drake (1992), Drake and Weyman-Jones (1996) and Simper (1998)). 
The translog cost function has been shown to have stability problems when estimated with diverse cross sectional data, see Rossi (1985), Westbrook and Buckly (1990) and Shaffer (1998), and in banking where small intermediaries could bias estimates, see McAllister and McManus (1993). The potential of the translog cost function to exhibit instability implies that a robust testing procedure should be carried out before any analysis of the results is discussed. To ensure that the estimated translog function satisfies the necessary conditions for a cost function, the results of three regularity tests are also presented in Tables 2 and 3. The first test estimates the marginal costs of outputs 1, 2 and 3 (MC Y1, MC Y2 and MC Y3 respectively), which should be positive. Secondly, standard production theory requires that the own-price elasticities be negative, indicating a concave cost function (Con P1, Con P2 and Con P3). Finally, monotonicity is verified when the fitted input share equations (SH EQ2 and SH EQ3) are nonnegative. In addition, Tables 2 and 3 also present the Log Likelihood of the functions (L.L.) in order that likelihood ratio tests can be conducted to establish the preferred model. $^{2}$

\section{INSERT TABLE 2}

\section{INSERT TABLE 3}

Generally, each model performs well in terms of the necessary regularity conditions. For example, the marginal costs of outputs in stage 1AA were significant and positive for $100 \%$ of building societies for output $1,97.44 \%$ for output 2 and $98.51 \%$ for output 3. In addition, the curvature conditions are significantly negative for own price elasticities 2 and 3 at the mean and insignificant for input 1. This condition is satisfied for $41.79 \%$ of all building societies for input 1, and for $99.79 \%$ for input 2 and $92.96 \%$ for input $3 .^{3}$ Finally, the share equations are both significantly positive at the mean and this condition is satisfied at $100 \%$ of the data points. Hence, we can conclude that we are satisfied with the regularity of the translog cost functions over the sample period.

\footnotetext{
2 Following Shaffer (1998), using an argument from Mishkin (1990), we do not test for heteroscedasticity.

3 The acceptance criteria for input 1 increases to $54.16 \%$ when the branch control variables are dropped.
} 
In assessing which model fits the data best we conduct likelihood ratio tests starting from the most general and moving to the most specific model. In our analysis we divide the stages into two sub-categories; the model that includes the branch control variables (stage 1AA) and those that exclude the branch control variables (stages $1 \mathrm{~A}$ to 3B). There are two reasons for this split analysis. Firstly, the branch control variables have a substantial and significant effect on the scale economies estimates obtained (see Table 2), and therefore presents us with a different policy conclusion. This is potentially important as for many building societies branches are a very important component of their delivery channel. Previous studies such as Hardwick (1989 and 1990) and Drake (1992) incorporated branching in their cross-section translog cost function specifications. Hence, the inclusion of branching facilitates a more direct contrast of previous empirical economies of scale estimates.

Secondly, an important element of this paper is the testing of the impact of the entry/exit model and the technological change specification on the results derived from the Translog cost function. Having established the impact of branching in moving from models $1 \mathrm{AA}$ to model $1 \mathrm{~A}$, we chose to undertake the further sequential testing in the context of the standard translog specification, ie, excluding the various branching terms. Hence, the second stage analysis (see Table 3 ) considers the step down testing procedure from stage $1 \mathrm{~A}$ to stage $3 \mathrm{~B}$

Including the branch control variables, the likelihood ratio test statistic from stage $1 \mathrm{AA}$ to stage $1 \mathrm{~A}$ is equal to 178.56 , hence the most general specification is our overall preferred model. However, as explained previously, in directly testing the entry/exit conditions imposed on our model we begin with the most general model in the second sub-category, stage 1A. The likelihood ratio test statistic from stage $1 \mathrm{~A}$ to stage $2 \mathrm{~A}$ is equal to 861.12, rejecting the null hypothesis of imposing the condition that the entry/exit equations should be excluded from the model. The next stage of assessment between the models is from stage $2 \mathrm{~A}$ to $3 \mathrm{~A}$, where in the former cost function we have included entry and exit dummy variables and in the latter these are excluded. Following Dionne et al (1998), we can determine if there is an entry or exit bias in our model if the dummy variables are significantly different from zero. In model $2 \mathrm{~A}$ we find that they are insignificant, hence both entry and exit from the sample is exogenous (the likelihood ratio 
test statistic from stage $2 \mathrm{~A}$ to stage $3 \mathrm{~A}$ is insignificant with a value of 0.12 ). However, in order to track any possible bias in the complete system of estimations, we have included the entry and exit dummy variables within the cost function. In fact in stages $1 \mathrm{AA}$ and 1A the exit dummy variable parameters are negative ( -0.8038 and -0.6591 respectively) and significant. This is not surprising given the consolidation within the sector and hence the propensity for exit via either mergers or conversion to Plc bank status. This result does confirm, however, the importance of specifying these entry/exit dummy variables in the estimated cost function.

Overall, when including the branch control variables, the preferred stage 1AA model fits the data well, with an $\mathrm{R}^{2}$ for the cost function equal to 0.99 , and for cost share equations 2 and 3 equal to 0.63 and 0.50 respectively. ${ }^{4}$ We also find that in the entry and exit equations, $90 \%$ and $75 \%$ of estimated parameters respectively are significantly different from zero. When we exclude the branch control variables, stage $1 \mathrm{~A}$, the $\mathrm{R}^{2}$ for the cost function is still equal to 0.99, and for cost share equations 2 and 3 this declines slight to equal 0.52 and 0.45 respectively. We next discuss the results from the various stages of model estimation and examine how the re-balancing of the sample affects the economies of scale estimates.

\subsection{Economies of Scale.}

Table 2 presents the economies of scale and technological change estimates for the translog cost function specification incorporating the number of building society branches, stage 1AA. The inclusion of branching makes a marked difference to our mean economies of scale estimates which changes from 0.970 for stage 1A to 0.907 for stage 1AA when branching is incorporated, see also Table 3. A paired samples $t$-test which computes the differences between the two stages and tests whether the average differs

\footnotetext{
4 The models were estimated using a grid search procedure ensuring a global maximum utilising TSP. 4.4a. Stage 1AA model estimated 85 parameters with 47 significant at the $10 \%$ critical level (parameter estimates are excluded to save space).
} 
from 0 , results in a $\mathrm{t}$ statistic of -74.704 . Hence, the economies of scale estimates between stages 1AA and 1A should be treated as diverse estimates.

The economies of scale estimate of 0.907 is a highly significant result as it suggests that the UK building society industry is characterised by very substantial economies of scale. Furthermore, this level of scale economies greatly exceeds both those found in previous studies of UK building societies and the findings for financial institutions in general across many different countries. With respect to UK building societies, for example, Drake (1992) finds evidence of only modest economies of scale at the sample mean. The measure of economies of scale used is the inverse of the one used here. Hence, the scale economy measure of 1.02 found by Drake would translate into a figure of 0.98. Interestingly, Drake and Weyman-Jones (1996) found evidence of constant returns at the sample mean using a cross-section translog cost function without the incorporation of branching.

Table 3, which presents the economies of scale and technological change estimates for each cost function excluding the branch control variables, shows that the mean economies of scale estimates do not vary substantially as we move from stage $1 \mathrm{~A}$ to $2 \mathrm{~A}(0.970)$ and $3 \mathrm{~A}(0.966)$. However, a paired samples t-test shows that although there is a positive significant correlation between stage $1 \mathrm{~A}$ and $2 \mathrm{~A}(0.794)$, there is also a significant difference between the two stage averages ( $\mathrm{t}$ statistic $=-5.619$ ), as is found between stages $1 \mathrm{AA}$ and $1 \mathrm{~A}$ above.

An interesting feature of the results in Table 3, however, is that the results do seem to be sensitive to the exclusion of the technical change parameters. As we move from stages $1 \mathrm{~A}$ to $1 \mathrm{~B}$, for example, the mean economies of scale estimate increases from 0.970 to 0.985 (both significantly different from unity). ${ }^{5}$ Similar results are also obtained from stages $2 \mathrm{~A}$ to $2 \mathrm{~B}$ ( 0.966 to 0.984$)$. This finding suggests that the economies of scale evident for UK building societies may be attributable, at least in part, to the impact of new technology in banking and retail financial services. Hence, the failure to incorporate this impact, as in stages $2 \mathrm{~B}$ and $3 \mathrm{~B}$, may bias the economies of scale estimates upwards with the attendant possibility of erroneous policy implications. Indeed, the use of cross

\footnotetext{
5 A paired samples $\mathrm{t}$ test between stages $1 \mathrm{~A}$ and $1 \mathrm{~B}$ produced a significant difference between the two stage averages ( $\mathrm{t}$ statistic $=8.508)$.
} 
section samples, and the consequent failure to allow for technological change may account for the very modest levels of economies of scale found in previous studies.

An aim of the Dionne et al (1998) procedure is to ensure that no bias is introduced into modeling as is the case when samples are rebalanced. In addition to the results presented in this paper, therefore, we also rebalanced the sample for the purpose of comparison. The sample size consequently decreased from 86 to 69 societies and we obtained from a rebalanced stage 1AA model (B1AA) an $\mathrm{R}^{2}$ equal to 0.99 for the cost function and of 0.58 and 0.39 respectively for cost share equations 1 and 2 . The log likelihood was equal to 2402.62 and tests to determine whether this stage B1AA model satisfied the necessary conditions for a cost function produced results very similar to the unbalanced stage 1AA model. More importantly, however, the economies of scale estimates from stage B1AA increased from 0.907 (stage 1AA) to 0.915 (significantly different from unity). In addition, we find that rebalancing the sample leads to both technological change estimates becoming insignificant $($ TEC $=0.0021$ and TECHSB $=-$ $0.02812)$.

These results support the contention of Dionne et al that rebalancing samples can introduce bias into the results and provide a justification for the use of unbalanced panels in conjunction with an entry/exit methodology.

\subsection{The Size Efficiency Relationship}

Of potentially greater interest than the mean scale economy estimates, from a strategic and policy perspective, is information concerning the relationship between scale efficiency and the size of building societies. This information is provided in Tables 2 and 3 for the 5 size bands of building society defined previously. Beginning with our preferred model augmented with branching (stage 1AA), this produces the expected result that the largest potential economies of scale are available to the smallest societies $(\mathrm{OES} E=0.899$ and $\mathrm{OES} \mathrm{D}=0.894)$ and the potential scale economies decline with size $(\mathrm{OES} \mathrm{B}=0.925)$.

A particularly interesting feature of the results, however, is that the scale economy estimate begins to fall again as we move from group B to group A (OES A=0.916). In 
addition, a one-way ANOVA was estimated to determine whether there is a significant difference between the group mean economies of scale for stage 1AA. An F statistic of 15.353 rejects the null of equal asset group means. ${ }^{6}$

The latter result suggests that some of the larger building societies may experience more significant economies of scale than their smaller competitors. One possible explanation for this type of result is the impact of new technology. This hypothesis is given some credence by the fact that although TEC is typically not significant, the scale biased technological change measure (TECHSB) is negative and significant. This suggests that technological change causes larger building societies to be more efficient over time than their smaller competitors and hence is a potential source of observed economies of scale. It is also worth noting from Table 3 that the likelihood ratio tests reject the elimination of the third order technological change terms (i.e., stages $1 \mathrm{~A}$ to $1 \mathrm{~B}, 2 \mathrm{~A}$ to $2 \mathrm{~B}$, etc), thus emphasising the importance of allowing for the potential impact of new technology on costs in retail financial services.

A further important finding in these results is the evidence of pervasive and substantial economies of scale at all size levels within the UK building society industry. Again, this result is in marked contrast with the evidence provided in previous studies. Hardwick (1989), for example, concludes that "societies with assets of less than $£ 280 \mathrm{~m}$ can achieve statistically significant economies of scale, but that there are no significant economies to be achieved by the growth of larger societies" (p 1303). Similarly, Drake (1992) maintains that "scale economies are evident only for the C class societies, i.e., building societies with assets of between $£ 120 \mathrm{~m}$ and $£ 500 \mathrm{~m}$. For all other asset groups the evidence suggests that constant returns prevail as the scale economy measures are not significantly different from unity.

Possible explanations for the substantial difference between the scale economy estimates found in this paper and those found in previous studies relate to differences in the sample period used, the econometric methodologies employed, and the impact of technology. The earlier studies employed cross section data from the 1980s. In contrast,

\footnotetext{
${ }^{6}$ Re-balancing the sample gives an F statistic of 25.731 rejecting the null of equal asset group means. Post hypothesis tests (Scheffe) indicates that asset groups A/D, A/E, B/D, B/E, C/D A/B, A/C, A/D, A/E, B/C, $\mathrm{B} / \mathrm{D}, \mathrm{B} / \mathrm{E}$ and $\mathrm{D} / \mathrm{E}$ are significantly different (a range of post hypothesis tests produced the same results).
} 
this study uses panel data from the 1990s and uses a general to specific econometric methodology to test the robustness of the cost function estimation. In particular, our estimates specifically incorporate an entry/exit model in the context of an unbalanced panel as well as allowing explicitly for the impact of new technology.

Similar evidence of differences in scale economy estimates over time has also been found in the context of US banking. Berger and Mester (1997), for example, find that in every size class banks exhibited unexploited economies of scale. They argue that "these findings differ from most of those using 1980s data, in which large banks were typically found to be operating at constant returns to scale or with slight diseconomies of scale. In almost all cases, cost scale economies were exhausted well below $\$ 10 \mathrm{~m}$ in assets." (p 927). Furthermore, in explaining the differences between the results, they highlight differences in cost function specifications and the fact that "improvements in technology and applied finance may have reduced costs more for large banks than for small banks." (p 929).

Further inspection of Table 3 confirms that economies of scale estimates can be extremely sensitive to the particular cost function specification. Firstly, it clear that the unexploited economies of scale are much lower in the absence of the branching augmentation. Nevertheless, in stages 1A, 2A and 3A there are pervasive statistically significant economies of scale at all size levels. In stage $1 \mathrm{~A}$, for example, these range from 0.958 for group $\mathrm{E}$ to 0.987 for group A. When we remove the third order technological change parameters (stage 1A to stage 1B), however, this range changes from 0.977 to 0.997 and the economies of scale estimates for the largest group A and B societies are no longer significantly different from unity. Perhaps more significantly, however, when we move from stages $2 \mathrm{~A}$ to $2 \mathrm{~B}$ the nature of the size efficiency relationship is completely inverted. In stage $2 \mathrm{~A}$, for example, the scale economies range from 0.958 (group E) to 0.977 (group A). In stage 2B, however, the range is from 0.993 (group E) to 0.969 (group A).

It is clear, therefore, that a mis-specified model could produce extremely misleading strategic implications. The latter results, for example, would suggest that the smallest building societies would be likely to be at a significant disadvantage relative to their larger competitors, but that they could not expect to see significant unit cost 
reductions from either organic growth or mergers with other relatively small building societies. The obvious strategic implication would be that these small societies should merge with, or transfer their engagements to, much larger building societies with the potential to exhibit considerable economies of scale.

In contrast, our preferred branch augmented stage 1AA model suggests that there are very significant unexploited scale economies at all size levels and that the smaller societies can generate cost efficiency gains from both organic growth and smaller scale mergers.

\section{Conclusions}

This paper produces important new evidence on the issue of economies of scale in UK building societies and thereby provides insights in respect of the size-efficiency relationship in the relatively neglected area of UK retail banking/retail financial services.

Our results echo the findings of Berger and Mester (1997) for the US and suggest that economies of scale estimates can be extremely sensitive to the cost model estimated. Using a general to specific modeling procedure which incorporates both an entry/exit model and a technological change specification we are able to identify a preferred cost model which produces empirical scale economy estimates very different from those obtained in previous research.

In contrast to previous studies, our results are entirely consistent with the recent merger and consolidation wave in banking and financial services as we find substantial and pervasive economies of scale for all sizes of building societies. We also find evidence that technological progress tends to reduce the costs of larger societies relative to their smaller competitors, thereby enhancing potential economies of scale. These results suggest a strong cost reducing rationale for mergers even with respect to relatively large building societies with assets of over $£ 5$ billion.

Hence, we would expect to see further mergers/consolidation within the UK retail financial services sector, particularly when our evidence concerning economies of scale and technology effects are combined with the rationalisation potential which mergers 
bring. With the arrival of new delivery channels such as telephone and internet banking, many financial services organisations are finding that the rationalisation of branches, infrastructure and staff is more easily accomplished following a merger in which the costly duplication of resources can be eliminated.

There has been considerable debate in the literature and amongst analysts concerning the future of smaller building societies. One view is that these institutions can survive by being highly focused on a narrow range of products, and by cultivating their local presence. This view, however, rests on the assumption that a narrow focus can deliver a relatively low cost base. While this may facilitate X-efficiency (operating closer to the minimum attainable costs for a given output level) it can do nothing to alleviate the problems of scale inefficiency ( failure to operate at the minimum efficient scale). Previous results have suggested that this is not a serious problem as only modest economies existed and these were exhausted at relatively low asset levels. The new evidence provided in this paper, however, suggests that smaller societies may be in a much more vulnerable position. Considerable scale economies appear to prevail at all asset sizes and the smallest building societies appear to have the largest unexploited economies of scale. Hence, other things equal (such as X-efficiency), these smaller societies would be expected to exhibit the highest unit costs. Our evidence suggests that these societies will also benefit less in a dynamic context from the cost reducing potential of new technology. Clearly, these pressures are likely to intensify in an increasingly competitive financial services marketplace and may well result in increased numbers of mergers involving the smaller building societies.

Due to the nature of the sample analysed, our results do not allow us to provide any insights concerning the nature of scale economies for very large institutions such as Lloyds Bank or Nat West. Hence, we cannot provide any empirical evidence pertaining to mergers such as Lloyds-TSB or Nat West-Royal Bank of Scotland. The agenda for future research should therefore include an analysis of the size-efficiency relationship with respect to large-scale banks and financial services organisations, and also an examination of X-inefficiency as well as scale inefficiency. 
Table 1.

Variable Descriptions and Summary Statistics.

\begin{tabular}{lllll}
\hline Variables & Mean & Std. Dev & Min & Max \\
\hline P1: Interest Price on Deposits & 0.0589 & 0.0139 & 0.0085 & 0.1042 \\
P2: Employment Price & 18.0173 & 6.0111 & 3.8947 & 103.8459 \\
P3: Other Expenses Price & 0.8147 & 0.6077 & 0.2242 & 6.4894 \\
Y1: Mortgages & 2160553.9 & 6765392.3 & 4738.00 & 7.18 D+07 \\
Y2: Other Loans & 116864.0 & 327457.0 & 183.00 & 2900763.0 \\
Y3: Commercial Assets & 196817.9 & 598422.2 & 447.11 & 5434700.0 \\
\hline
\end{tabular}

Output variables are in $£ 000$ s.

Table. 2

UK Building Societies (1992 - 1997) Summary Results for Augmented Branch Entry/Exit Technological Change Stage 1AA.

\begin{tabular}{|c|c|c|c|c|c|}
\hline \multicolumn{6}{|c|}{ Necessary Conditions and Stability Tests for Flexible Functional Forms. } \\
\hline MC Y1 & $0.7605 * *$ & MC Y2 & $0.0678 * *$ & MC Y3 & -0.0247 \\
\hline $100 \%$ & $(0.0579)$ & $97.44 \%$ & $(0.0200)$ & $98.51 \%$ & $(0.2261)$ \\
\hline Con P1 & 0.1300 & Con P2 & $-0.4709 * *$ & Con P3 & $-0.4852 * *$ \\
\hline $41.79 \%$ & $(0.0521)$ & $99.79 \%$ & $(0.0647)$ & $98.51 \%$ & $(0.0748)$ \\
\hline \multirow[t]{2}{*}{ L. L. } & 3367.35 & SH EQ 2 & $0.0968 * *$ & SH EQ 3 & $0.1078 * *$ \\
\hline & & $100 \%$ & $(0.0014)$ & $100 \%$ & $(0.0062)$ \\
\hline \multicolumn{6}{|c|}{ Summary Descriptive Statistics } \\
\hline & Cost Fn. & SH EQ 2 & SH EQ 3 & Entry EQ & Exit EQ \\
\hline m.d.v. & 9.9589 & 0.0983 & 0.1208 & 0.0171 & 0.0299 \\
\hline s.e. reg. & 0.1557 & 0.0180 & 0.0287 & 0.1737 & 0.1963 \\
\hline $\mathrm{R}^{2}$ & 0.9942 & 0.6256 & 0.4947 & 0.0010 & 0.0163 \\
\hline \multicolumn{6}{|c|}{ Scale Economies and Technological Change Estimates } \\
\hline \multirow[t]{2}{*}{ OES } & $0.9073^{\mathrm{a}}$ & OES C & $0.9083^{\mathrm{a}}$ & TEC & 0.0239 \\
\hline & $(0.0359)$ & & $(0.0359)$ & & $(0.0123)$ \\
\hline \multirow[t]{2}{*}{ OES A } & $0.9184^{\mathrm{a}}$ & OES D & $0.8942^{\mathrm{a}}$ & TECSHB & $-0.0359 * *$ \\
\hline & $(0.0393)$ & & $(0.0369)$ & & $(0.0134)$ \\
\hline \multirow[t]{2}{*}{ OES B } & $0.9249^{\mathrm{a}}$ & OES E & $0.8991 \mathrm{a}$ & & \\
\hline & $(0.0348)$ & & $(0.0358)$ & & \\
\hline
\end{tabular}

(Standard errors are in parentheses; $* *$ denotes significance at the $1 \%$ and $*$ denotes significance $5 \%$ critical level; \% is the percentage number of UK building societies that fail to reject the null hypothesis of the necessary relevant condition; L. L. is the Log Likelihood of the function; m.d.v is the mean of the dependent variable, s.e. reg is the standard error of the regression; and ${ }^{\mathrm{a}}$ denotes significantly different from one at the $5 \%$ critical level). 
Table 3.

UK Building Societies (1992 - 1997) Summary Results for Entry/Exit Technological Change Model.

\begin{tabular}{|c|c|c|c|c|c|c|}
\hline & \multicolumn{2}{|l|}{ Stage 1} & \multicolumn{2}{|l|}{ Stage 2} & \multicolumn{2}{|l|}{ Stage 3} \\
\hline & A & B & A & $\mathrm{B}$ & A & B \\
\hline \multirow[t]{2}{*}{ L. L. } & 3278.07 & 3110.93 & 2847.51 & 2521.46 & 2847.45 & 2511.33 \\
\hline & \multicolumn{6}{|c|}{ Necessary conditions and Stability Tests for Flexible Functional Forms. } \\
\hline \multirow[t]{2}{*}{ MC Y1 } & $0.8109 * *(0.0478)$ & $0.7757 *(0.0814)$ & $0.7917 * *(0.0264)$ & $0.7595 * *(0.0427)$ & $0.7923 * *(0.0261)$ & $0.7842 * *(0.0356)$ \\
\hline & $100 \%$ & $100 \%$ & $100 \%$ & $100 \%$ & $100 \%$ & $100 \%$ \\
\hline \multirow[t]{2}{*}{ MC Y2 } & $0.0682 * *(0.0165)$ & $0.0698 * *(0.0261)$ & $0.0548 * *(0.0099)$ & $0.0502 * *(0.0196)$ & $0.0547 * *(0.0098)$ & $0.0543 * *(0.0183)$ \\
\hline & $98.51 \%$ & $99.57 \%$ & $97.44 \%$ & $100 \%$ & $97.23 \%$ & $100 \%$ \\
\hline \multirow[t]{2}{*}{ MC Y3 } & $-0.0408 \quad(0.0945)$ & $0.1400 * \quad(0.0841)$ & $0.0199 \quad(0.1095)$ & $0.1747 * *(0.0461)$ & $0.0179 \quad(0.0365)$ & $0.1461 * *(0.0387)$ \\
\hline & $100 \%$ & $99.79 \%$ & $99.36 \%$ & $100 \%$ & $99.15 \%$ & $100 \%$ \\
\hline \multirow[t]{2}{*}{ Con P1 } & $0.0270 \quad(0.0542)$ & $-0.1113 * *(0.0204)$ & $-0.0318 \quad(0.6183)$ & $-0.0977 * *(0.02141$ & $-0.0319 \quad(0.0513)$ & $-0.0866 * *(0.0214)$ \\
\hline & $54.16 \%$ & $100 \%$ & $64.82 \%$ & $99.79 \%$ & $64.82 \%$ & $99.79 \%$ \\
\hline \multirow[t]{2}{*}{ Con P2 } & $-0.5577 * *(0.0721)$ & $-0.5419 * *(0.0368)$ & $-0.5726 * *(0.0633)$ & $-0.5357 * *(0.0323)$ & $-0.5729 * *(0.0632)$ & $-0.5233 * *(0.0288)$ \\
\hline & $100 \%$ & $100 \%$ & $100 \%$ & $100 \%$ & $100 \%$ & $100 \%$ \\
\hline \multirow[t]{2}{*}{ Con P3 } & $-0.5741 * *(0.0664)$ & $-0.6661 * *(0.02874$ & $-0.3919 * *(0.0899)$ & $-0.6102 * *(0.0333)$ & $-0.3923 * *(0.0085)$ & $-0.5776 * *(0.0284)$ \\
\hline & $99.79 \%$ & $100 \%$ & $80.38 \%$ & $100 \%$ & $80.59 \%$ & $100 \%$ \\
\hline
\end{tabular}




\begin{tabular}{|c|c|c|c|c|c|c|}
\hline & Stage 1 & & Stage 2 & & & \\
\hline & $\mathrm{A}$ & $\mathrm{B}$ & & $\mathrm{B}$ & $\mathrm{A}$ & \\
\hline SH EQ 2 & $0.1016 * *(0.0020)$ & $\begin{array}{c}0.0984 * *(0.0017) \\
100 \%\end{array}$ & $100 \%$ & $0.0981 * *(0.0014)$ & $\begin{array}{c}0.1009 * *(0.0019) \\
100 \%\end{array}$ & $100 \%$ \\
\hline SH EQ 3 & $100 \%$ & $0.1209 * *(0.0022)$ & $\begin{array}{c}0.1304 * *(0.0026) \\
100 \%\end{array}$ & $100 \%$ & $0.1304 * *(0.0026)$ & $\begin{array}{c}0.1198 * *(0.0022) \\
100 \%\end{array}$ \\
\hline \multirow[t]{2}{*}{ OES } & $\begin{array}{ll}\mathrm{a} & (0.0051)\end{array}$ & $\begin{array}{ll}\mathrm{a} & (0.0078)\end{array}$ & $\begin{array}{ll}\mathrm{a} & (0.0037)\end{array}$ & ${ }^{\mathrm{a}}(0.0072)$ & $\begin{array}{ll}\mathrm{a} & (0.0037)\end{array}$ & ${ }^{\mathrm{a}}(0.0065)$ \\
\hline & $0.9867^{\mathrm{a}}$ & $0.9970 \quad(0.0106)$ & $0.9768 \quad(0.0068)$ & $0.9693 \quad(0.0238)$ & a $(0.0068)$ & \\
\hline OES B & $0.9729 \quad(0.0057)$ & $0.9879 \quad(0.0086)$ & a $(0.0046)$ & & $0.9650^{\mathrm{a}}$ & $0.9809 \quad(0.0114)$ \\
\hline \multirow[t]{4}{*}{ OES C } & a $(0.0051)$ & & $0.9645^{\mathrm{a}}$ & $0.9874 \quad(0.0068)$ & $0.9646 \quad(0.0038)$ & $0.9873(0.0064)$ \\
\hline & $0.9631^{\mathrm{a}}$ & $0.9820^{\mathrm{a}}$ & $0.9655^{\mathrm{a}}$ & $0.9882 \quad(0.0109)$ & $0.9655 \quad(0.0053)$ & $0.9887 \quad(0.0099)$ \\
\hline & $0.9577^{\mathrm{a}}$ & $0.9775^{\mathrm{a}}$ & $0.9581^{\mathrm{a}}$ & $0.9933(0.0141)$ & $0.9582(0.0063)$ & $0.9927 \quad(0.0132)$ \\
\hline & $0.0097 \quad(0.0086)$ & & $0.0073 \quad(0.0043)$ & & & \\
\hline TECSB & $-0.0383 * *(0.0138)$ & & & & $-0.0534 * *(0.0173)$ & \\
\hline
\end{tabular}

Stage $1 \mathrm{~A} \quad$ rd order time polynomial; Stage 1 B: Cost function with entry/exit dummies and entry/exit

equations; Stage 2 A: Cost function with entry/exit dummies and 3 order time polynomial; Stage 2 B: Cost function with entry/ exit dummies; Stage 3 A: Cost function with 3 order time polynomial; Stage 3 B: Standard $1^{\text {st }}$

$5 \%$ critical level; \% is the percentage number of UK building societies that fail to reject the null hypothesis of the necessary relevant condition; and L. L. is the Log Likelihood of the function). 



\section{References}

Allen, L., and Rai. A. "Operational Efficiency in Banking: An International Comparison. Reply to the Comment." Journal of Banking and Finance 21 (1997), 1451-1455.

Bauer, P W., Berger, A N, Ferrier, G D., and Humphrey, D. B. "Consistency Conditions for Regulatory Analysis of Financial Institutions: A Comparison of Frontier Efficiency Methods." Journal of Economics and Business 50 (1998), 85-114.

Berger, A N. "'Distribution - Free" Estimates of Efficiency in the U.S. Banking Industry and Tests of the Standard Distributional Assumptions.” The Journal of Productivity Analysis 4 (1993), 261-292.

Berger, A N. and D B. Humphrey. "Efficiency of Financial Institutions: International Survey and Directions for Future Research.” European Journal of Operations Research 98 (1997), 175-212.

Berger, A N., Leusner, J. H. and Mingo, J. J. "The Efficiency of Bank Branches," Journey of Monetary Economics 40 (1997), 141-162.

Craig. V. C., “Japanese Banking: A Time of Crisis?” FDIC Banking Review 11(2) (1998).

Diago, S., Yonetani, T., and Marumo, K. "Banks Recapitalization Policies in Japan and their Impact on the Market." Journal of International Financial Markets, Institutions and Money 9 (1999), 223-246.

DeYoung, R. “A Diagnostic Test for the Distribution - Free Efficiency Estimator: An Example using U.S. Commercial Bank Data." European Journal of Operational Research 98 (1997), 243-249.

DeYoung, R. "Management Quality and X-Inefficiency in National Banks." Journal of Financial Services Research 13(1) (1998), 5-22.

Dionne, G., Gagne, R., and Vanasse, C. "Inferring Technological Parameters from Incomplete Panel Data.” Journal of Econometrics 87 (1998), 303-327.

Drake, L. "Economies of Scale and Scope in UK Building Societies: An Application of the Translog Multiproduct Cost Function.” Applied Financial Economics 2 (1992), 211-219.

Drake, L., and Weyman-Jones, T G. "Productive and Allocative Inefficiencies in U.K. Building Societies: A Comparison of Non-Parametric and Stochastic Frontier Techniques." Manchester School of Economic and Social Studies 114(1) (1996), 22-37. 
Edwards. J., and Ogilie. S. "Universal Banks and German Industrialisation: A Reappraisal." Economic History Review 99(3) (1998), 427-446.

Fukuyama, H. "Technical and Scale Efficiency of Japanese Commercial Banks: A NonParametric Approach.” Applied Economics 25 (1993), 1101-1112.

Gagne, R., and Ouellette, P. "On the choice of functional forms: Summary of a Monte Carlo experiment,” Journal of Business and Economic Statistics 16(1) (1998), 118-124.

Glass. J. C. and McKillop., D. G. "An Empirical Analysis of Scale and Scope Economies and Technological Change in an Irish Multiproduct Banking Firm.” Journal of Banking and Finance 16 (1992), 423-437.

Harui, H. "Japan's Financial Problems: Causes and Prospects." Loughborough University Banking Centre Research Paper. No. 108/97 (1997).

Hasan, I, and Hunter, C. H. "Efficiency of Japanese Multinational Banks in the United States." Research in Finance 14 (1996), 157-173.

Hisnanick, J. J., and Kymn, K. O. "Modelling Economies of Scale: The Case of US Electric Power Companies.” Energy Economics (1999), 225-237.

Hoshi. T., and Kashyap. A. "The Japanese Banking Crisis: Where did it come from and How Will it End?" NBER Working Paper No. W7259 (1999).

Hunter, W. C., and Timme, S. G. "Technology Change in Large U.S. Commercial Banks." Journal of Business 64(3) (1991), 339-362.

Hunter, W. C., and Timme, S. G. "Core Deposits and Physical Capital: A Reexamination of Bank Scale Economies and Efficiency with Quasi - Fixed Inputs.” Journal of Money, Credit and Banking 27(1) (1995), 165-185.

Izawa, H., and Tsutsui, Y. "Managerial Objectives in Japanese Banking: a Test of the Expense Preference Hypothesis.” Applied Financial Economics 8 (1998), 89-99.

McAllister, P. H and McManus, D. "Resolving the Scale Efficiency Puzzle in Banking." Journal of Banking and Finance 17 (1993), 389-405.

Mester., L. J., (1997), "Measuring Efficiency at U.S. banks: Accounting for Heterogeniety is Important.” European Journal of Operational Research 98 (1997), 230-242.

Mishkin, F. S. "Does Correcting for Heteroscedasticity Help." Cambridge, M.A: NBER Technical Working Paper 88 (1990). 
Olley, G. S., and Pakes. A. "The dynamics of productivity in the telecommunications equipment industry." Econometrica 64(6) (1996), 1263-1297.

Panzar., J. C, and Willig., R. D, "Economies of Scale in Multi-Output Production." Quarterly Journal of Economics 91 (1977) 481-94.

Pulley. L. B. and Braunstein. Y. M. "A Composite Cost Function for Multiproduct Firms with an Application to Economies of Scope in Banking." Review of Economics and Statistics 74 (1992), 221-230.

Rossi, P. E. "Comparison of Alternative Functional Forms in Production." Journal of Econometrics 30 (1985), 345-361.

Rossi. C. C. "Mortgage Banking Cost Structure: Resolving an Enigma." Journal of Economics and Business 50 (1998), 219-234.

Shaffer, S. "Functional Forms and Declining Average Costs." Journal of Financial Services 14(2) (1998), 91-115.

Simper, R. "Economies of Cost in the UK Building Society Industry." The Service Industries Journal 18(4) (1998), 109-125.

Simper, R. "Economies of Scale in the Italian Saving Bank Industry." Applied Financial Economics 9 (1999), 11-19.

Sealey, C. W. and Lindley, J. T. "Inputs, Outputs and the Theory of Production and Costs at Depository Financial Institutions.” Journal of Finance 32(4) (1977), 1251-65.

Tachibanaki, T., Mitsui. K., and Kitagawa. H. "Economies of Scope and Shareholding of banks in Japan." Journal of the Japanese and Institutional Economies 5 (1991), 261-281.

Thomas, R. L. Introductory Econometrics, Longman, London (1985).

Walker. G. "Economies of Scale in Australian Banks 1978-1990." Australian Economic Notes 37(1) (1998), 71-87. 

